\title{
THE USE OF N-BUTYL CYANOACRYLATE ADHESIVE IN THE CLOSURE OF MUCO- PERIOSTEAL FLAP AFTER THE SURGICAL EXTRACTION OF IMPACTED MANDIBULAR THIRD MOLAR
}

\author{
Rewainy $\mathrm{M}^{1}$, Osman $\mathrm{S}^{2}$, El-prince $\mathrm{N}^{2}$
}

\begin{abstract}
:
Introduction: Surgical extraction of impacted third molars has become a routine procedure in most of dental clinics. Tissue adhesives based on Nbutyl cyanoacrylate are employed as a non-suture method for intra-oral postsurgical wound closure.

Objectives: Evaluation of the clinical post-operative complications after the use of N-butyl cyanoacrylate soft tissue adhesive in closure of mucoperiosteal flaps after the surgical extraction of impacted mandibular third molars compared to the use of conventional silk sutures.

Materials and methods: This study was conducted on twenty patients of both sexes ranging from 20 to 30 years of age.Patients were divided equally into two groups (Study and control groups) each with mesioangular impacted mandibular third molar (class II position B according to Pell and Gregory's classification). After the surgical extraction of impacted teeth the flaps were closed using PeriAcryl 90 (Glustitch corporation, Delta, BC, Canada) soft tissue adhesive in the study group and using 3/0 silk sutures in the control group. Patients were evaluated for pain, bleeding, trismus, facial swelling, wound dehiscence and local reaction.

Results: There was a statistically significant reduction of pain, bleeding, trismus, wound reaction on using the N-butyl cyanoacrylate (PeriAcryl 90) compared to sutures, concerning wound dehiscence and facial swelling, the results of both materials were nearly the same.

Conclusion: The use of the N-butyl cyanoacrylate (PeriAcryl 90) for the closure of mucoperiosteal flaps is a reliable method that can overcome most of complications faced on using conventional silk sutures in addition to ease of manipulation, time saving and safety factors.
\end{abstract}

Key words : impacted third molar , mucoperiosteal flap, cyanoacrylate adhesive , PeriAcryl 90

1 Bachelor in dentistry, BDS, Faculty of Dentistry, University of Alexandria.

2 Professor of Oral and Maxillofacial Surgery, Faculty of Dentistry, Alexandria University.

\section{INTRODUCTION}

Wound closure is a mainstay procedure in day-to-day practice of oral and maxillofacial surgery, either during the treatment of injuries or defects. The surgical removal of the impacted third molar tooth is often associated with several post-operative complications including: pain, trismus, edema and other events of discomfort. These events are influenced by several factors include: the severity of impaction, the technique employed for the impaction and the difficulty of the operation (1-3).

The correct technique of suturing enables good wound closure through proper healing mechanism. Unfortunately, incompatibility with tissues may cause foreign body reactions and fistula formation. Also over-tight sutures may lead to ischemia and necrosis, ending by what is known as "burst" suture line. Braided silk also has a phenomenon known as "wicking" making it a site of retention of bacteria followed by secondary infection, as the knots represent a favorable place for bacterial colonies $(4,5)$.

As a new era, tissue adhesives have adopted the idea of sutureless wound closure. This idea has started by using the fibrin adhesive system "FAS", derived from human plasma, to promote hemostasis and wound healing, especially in the control of post-extraction hemorrhage in patients with bleeding disorders. The risk of viral transmission was an obstacle against the "FAS", so a synthetic bio-adhesive material was essential (6-8).

Cyanoacrylates are synthetic surgical adhesives found to be effective in the closure of low-tension lacerations. Its ease in application, immediate hemostasis, bacteriostatic effect and rapid adhesion that saves time were the main advantages of them.Cyanoacrylates were first introduced by Coover et al at 1959, the material has the chemical formula "H2C = C $(\mathrm{CN})$ COOR", where the "R" group can be substituted by any alkyl group ranging from methyl to decyl.
The earlier methyl forms were histotoxic, alpha and ethyl forms also were incompatible and were not used in humans (9-11).

If cyanoacrylate glue is placed on a dry surface the glue does not bond with the surface. The setting of cyanoacrylates is accelerated by water or moisture (saliva in oral cavity), as with the slightest amount of water, that could include the moisture in the air; the molecules of the glue react and form a tight chain between the two surfaces being bonded. This happens within 10-15 seconds. Cyanoacrylates generate its own heat for faster curing through an exothermic reaction. This heat may damage the soft tissue and hamper its blood supply. To avoid this; manufacturers have incorporated long chains of methyl group due to which the polymerization process is elongated and the rate of heat generation prolongs $(12,13)$.

These materials are not absorbable and are sloughed from the surface of the skin and mucosa 7-10 days after adhesive application. In the maxillofacial field, it has been used for wound closure on extraction sockets, face, sinus perforation in sinus lift, gingivectomy, mucogingival flaps, biopsy, superficial oral ulcerations, recurrent multiple aphthae and leukemia, and other sites in general surgery (14-18).

$\mathrm{N}$-butyl cyanoacrylate is one of the biocompatible tissue adhesives that displaysbacteriostatic and hemostatic effects. In addition, it saves time compared to the conventional sutures, and doesn't need follow-up. In dentistry, it has been used in various branches as post extraction dressings and hemostatic agents, pit and fissure sealants, pulp capping materials, root canal sealant, retrograde filling materials and also as a temporary splinting material for traumatized teeth. . Butyl esters provide stronger bond, but are rigid. Octyl ester, while providing weaker bond, are more flexible $(10,19,20)$.

This study aims at the clinical evaluation of N-butyl cyanoacrylate adhesive (PeriAcryl 90) as an alternative to 
conventional sutures after the surgical extraction of impacted mandibular third molars, through comparing the post-operative complications of each.

\section{MATERIALS AND METHODS}

A clinical study was conducted on twenty patients of both sexes aging between 18-30 years, selected from the outpatient clinic of the Oral and Maxillofacial Surgery department, Faculty of Dentistry, Alexandria University. The patients were randomly selected, each had an impacted mesioangular mandibular third molar, classified as class II position B, according to Pell and Gregory's classification (21).

The selected patients were randomly allocated into two study groups as follows:

Control group: Ten patients undergoing surgical extraction of impacted mandibular third molar and the wound closure with $3 / 0$ silk suture material in interrupted fashion.

Study group: Ten patients undergoing surgical extraction of impacted mandibular third molar and the wound closure with a blend of N-butyl cyanoacrylate and 2-Octyl cyanoacrylate (PeriAcryl 90).

\section{Inclusion criteria:}

1- Age between 18-30 years.

2- All patients had an impacted mesioangular mandibular third molar (Class II position B, according to Pell and Gregory's classification).

\section{Exclusion criteria:}

1. Patients with any systemic diseases.

2. Pregnant or lactating patients.

3. Patients with signs of pericoronitis or active infection.

4.Patients with habits as smoking, addiction and mouth breathing are excluded.

The material in use is supplied in the form of kits; each contains a plastic vial of $5 \mathrm{ml}$, containing a purified blend of: $\mathrm{N}$ butyl cyanoacrylate and 2-octyl cyanoacrylate. Disposable plastic pipettes are supplied for ease of application. Also its distinctive violet color allows this precise application to the target incision line. The multi-use kit is shown in Figure (1).

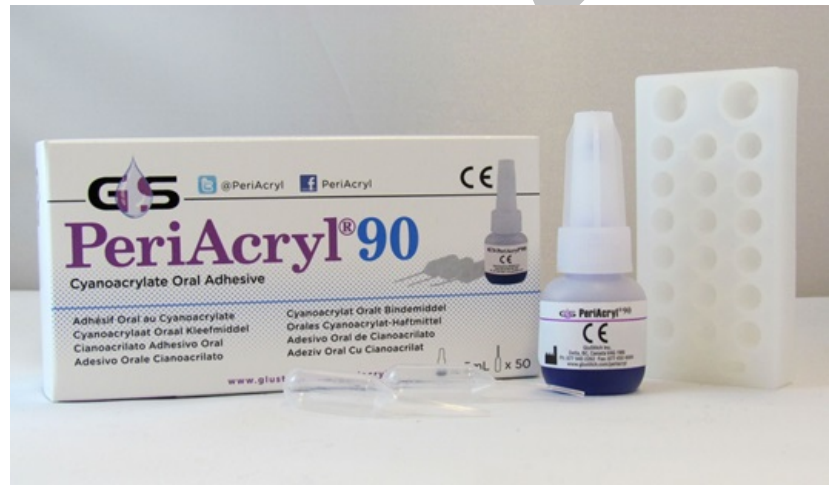

Fig. 1: Multiuse kit of PeriAcryl soft tissue cyanoacrylate adhesive.

\section{Pre-operative phase}

A written informed consent was taken from each patient prior to any surgical procedure. Pre-surgical clinical and radiographic examination through an orthopantomogram were taken to assess the third molar position and angulation.

Pre-operative recording of facial measurements to draw a base line for post-operative edema, according to Gabka and Matsumra's method of assessment of post-operative facial edema (22).

The method includes measuring the distance from attachment of the ear lobe to the soft tissue pogonion, distance from the ear lobe, to the corner of mouth, then the distance from outer canthus of eye to angle of mandible. The sum of these 3 measurements is recorded preoperatively to represent the baseline number used in the comparison with the measurements taken post-operatively after 24 hours, 3 days and 7 days.

A mouth rinse with $15 \mathrm{ml}$ of $0.12 \%$ solution of Chlorhexidine gluconate (Hexitol, The Arab Drug Co. (ADCO), Egypt) before the procedure is advised for all patients in both groups.

\section{Operative phase:}

The standard surgical technique was applied by adequate exposure of the impacted lower third molar was performed under local anesthesia of $2 \%$ Mepivicaine Hydrochloridewith1:80, 000 Adrenaline (Mepivicaine - L: Alexandria Co. for Pharmaceuticals and Chemical Industries, Alexandria, Egypt).

A mucoperiosteal flap was started one and half centimeter distal to the second molar, followed by a buccal oblique incision that was performed immediately mesial to the lower second molar at $45^{\circ}$ degrees. The cut should be clean and precise without lacerations made with the scalpel blade bard parker no. 15 .

The flap was reflected by a periosteal elevator to allow adequate field for guttering.Guttering was performed using a cylindrical surgical bur mounted to a high-speed turbine with sufficient cooling system as shown in Figure (2).

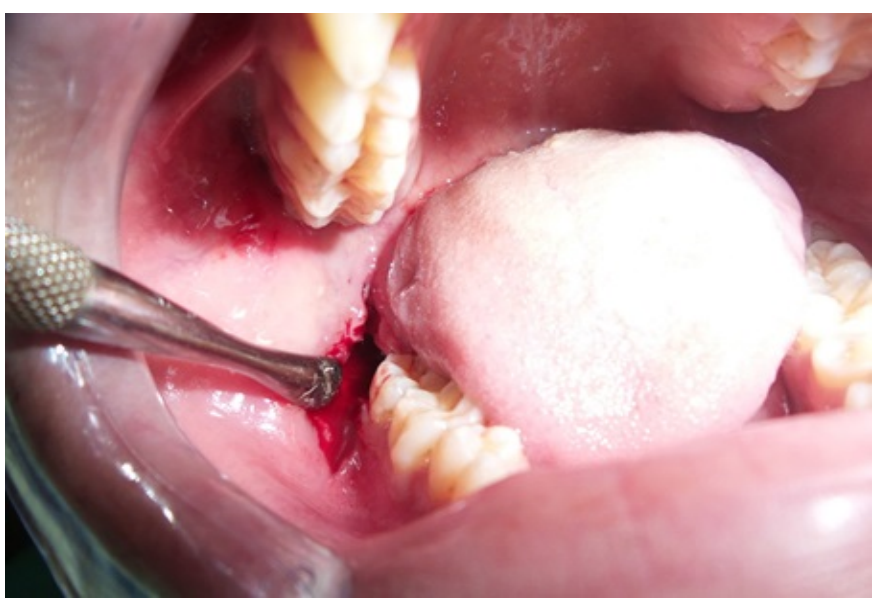

Fig. 2: Incision and elevation of the muco-periosteal flap

Methodology: 
The impacted third molar was sectioned using a suitable diamond stone, then elevated with a suitable straight elevator, after adequate guttering is achieved, wound debridement from all bone chips and debris was then made with sterile saline solution.

All sharp edges were smoothened with a bone file and any remnants of the dental follicle were removed, then a final irrigation was done and the wound edges were ready for closure, as shown in Figure (3).

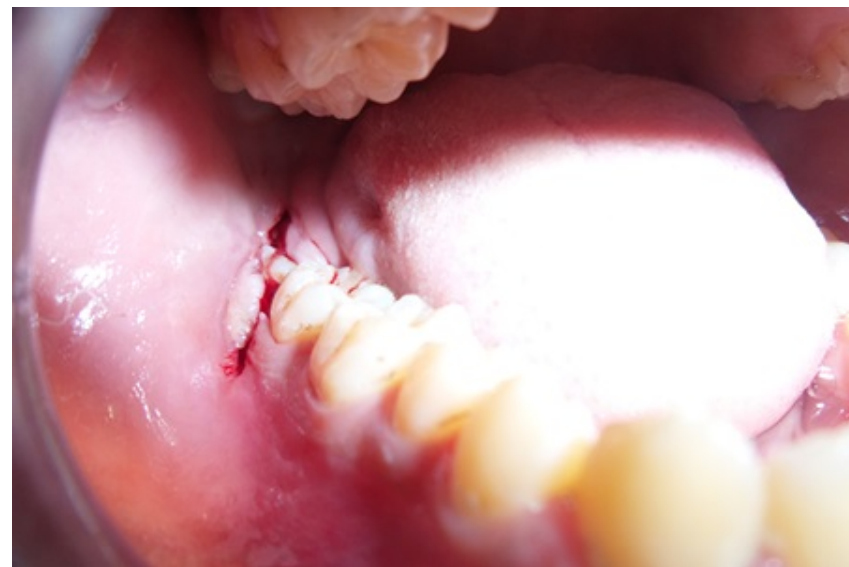

Fig. 3: Flap is ready for closure

\section{Wound closure: \\ In control group}

The flap was repositioned and closed with $3 / 0$ silk sutures in an interrupted fashion in all patients. The sutures were removed after 7 days.

\section{In study group}

The flap was repositioned and isolated with sterile dry gauze. After adequate isolation, wound was closed by using two thin layers of PeriAcryl 90, as shown in Figure (4).

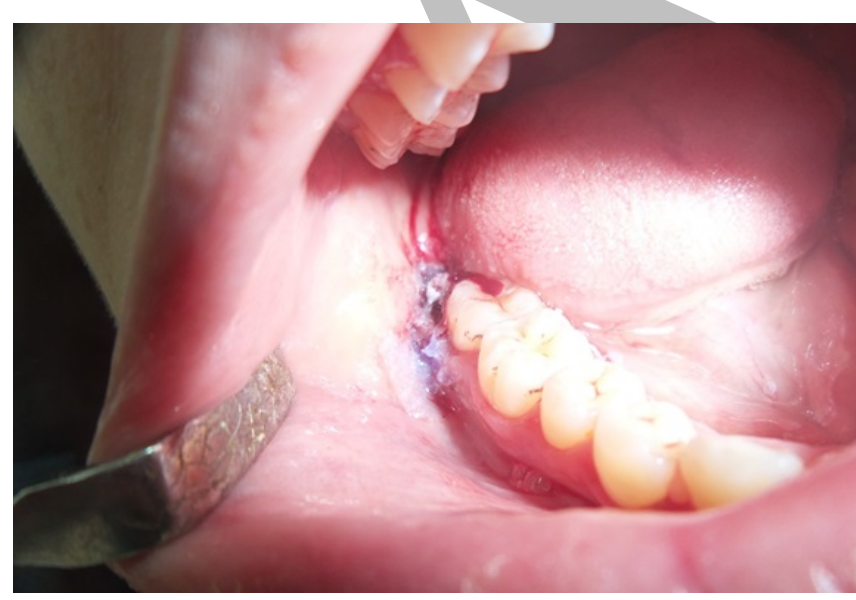

Fig. 4: Wound closure using PeriAcryl 90 cyanoacrylate adhesive

The first layer was applied on the incision line by the use of the supplied pipette, followed by another layer after 20 seconds. Excess drops flowing over were removed by blotting action by a cotton tip applicator, then cleaned with a piece of gauze wet with sterile saline.
The material was then allowed to stand for 1-2 minutes to adhere the incised tissues. Special care should be taken to avoid the flow of the material to the juxtaposed tissues.

\section{Post-operative phase:}

Patients in both groups were prescribed Amoxicillin 500 mgs (Amoxil 500 mgs, Glaxo-Smith-Klein) orallysupplemented antibiotic every 8 hours started the day before surgery and lasting for four days after, and Diclofenac potassium 50 mgs (Cataflam50 mgs, Novartis Pharmaceuticals Corporation) tablets when needed. Patients are instructed to apply ice packs at the operated side extraorally, they are also asked to rinse with $0.12 \%$ Chlorhexidine mouth rinse twice daily for 1 week.

\section{Follow-up phase:}

The patients were recalled after 2 days, 3 days and 7 days to evaluate all the subjective and objective criteria. The surgical areas are checked for visible signs of pain, bleeding, trismus, swelling, local reaction and wound dehiscence.

After 7 days sutures were removed, while cyanoacrylates sloughed off eliminating the need for a second visit, leaving the underlying mucosa in normal healing pattern as shown in Figure (5).

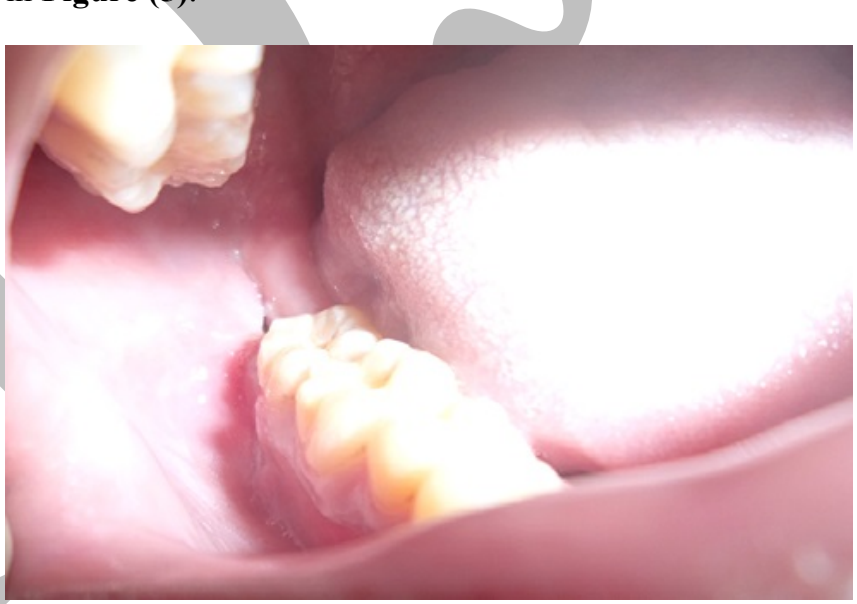

Fig. 5: One week post-operatively after closure with the adhesive

\section{Clinical Parameters:}

Various postoperative parameters were used to evaluate the study subjects, including: Pain, trismus, bleeding, local reaction and swelling were evaluated after first, third and seventh postoperative days. Wound dehiscence was evaluated after the first, second, third and seventh postoperative days.

Pain was evaluated with the Visual Analogue Scale of Pain: the scale consists of 5 levels of pain each were described in words to the patient and according to his own evaluation, one level was selected for a certain day.

Bleeding was evaluated using the Visual Analogue Scale of Bleeding: the scale consists of 5 levels of bleeding each pattern was described in words to the patient and according to his own evaluation, one level was selected for the day. 


\section{STATISTICAL ANALYSIS:}

Qualitative data were described using number and percent. Quantitative data were described using range (minimum and maximum), mean, standard deviation and median. Comparison between different groups regarding categorical variables was tested using Chi-square test. When more than $20 \%$ of the cells have expected count less than 5, correction for chi-square was conducted using Fisher's exact test.

McNemar-Bowker was used to analyze the significance between the different stages. The distributions of quantitative variables were tested for normality using Kolmogorov-Smirnov test, Shapiro-Wilk test and D'Agstino test, If it reveals normal data distribution, parametric tests was applied. If the data were abnormally distributed, nonparametric tests were used.

For normally distributed data, comparison between two independent population were done using independent t-test, comparison between different periods using ANOVA with repeated measures and Post Hoc test was assessed using Bonferroni adjusted. For abnormally distributed data, comparison between two independent populations was done using Mann Whitney. To compare between the different periods Wilcoxon signed ranks test was applied. Significance of the obtained results was judged at the $5 \%$ level.

\section{RESULTS}

The study was conducted on 20 patients, 12 males $(60 \%)$ and 8 females $(40 \%)$ that were equally and randomly grouped in 2 groups. All patients ranged 18-30 years of age, with mean age of 24 years.

\section{1- Pain:}

Data analysis has showed that the severity of pain in both groups was increased at the day of surgery, but the suture group recorded higher values on the pain scale after the first day making a significant difference between both groups $(\mathrm{P}$ 0.002). On the third day the difference between both groups was still present. The least significant difference was found by the seventh day post-operatively as individuals of both groups recorded nearly similar values on the pain scale (P 0.036). Data analysis is showed in Table (1).

\section{2- Bleeding}

Data analysis showed that postoperative bleeding with the cyanoacrylate adhesive method was highly diminished compared to the suture group , as $90 \%$ of the suture group individuals recorded elevated values on the bleeding index ( $P$ 0.001), while immediate hemostasis was achieved in most of patients of the adhesive group. On the third day after surgery, the difference was still present between both groups (P 0.001), by the seventh day postoperatively there was no difference between the two methods as most of individuals in both groups recorded zero bleeding values ( $\mathrm{P}$ $0.068)$. Data analysis is showed in Table (1).

\section{3- Trismus}

The difference was significant between both groups from the first day, as it was less marked trismus among patients of the cyanoacrylate adhesive group (P 0.004).After the third post-operative day the cyanoacrylate adhesive group showed much more better records, making the difference more significant, this means that the recovery in the adhesive group was much more rapid (P 0.002), after 7 days post-operatively, the difference was still present and significant. Data analysis is explained in Table (2).

Table (1): Comparison between the two studied groups according to pain scale and bleeding scale

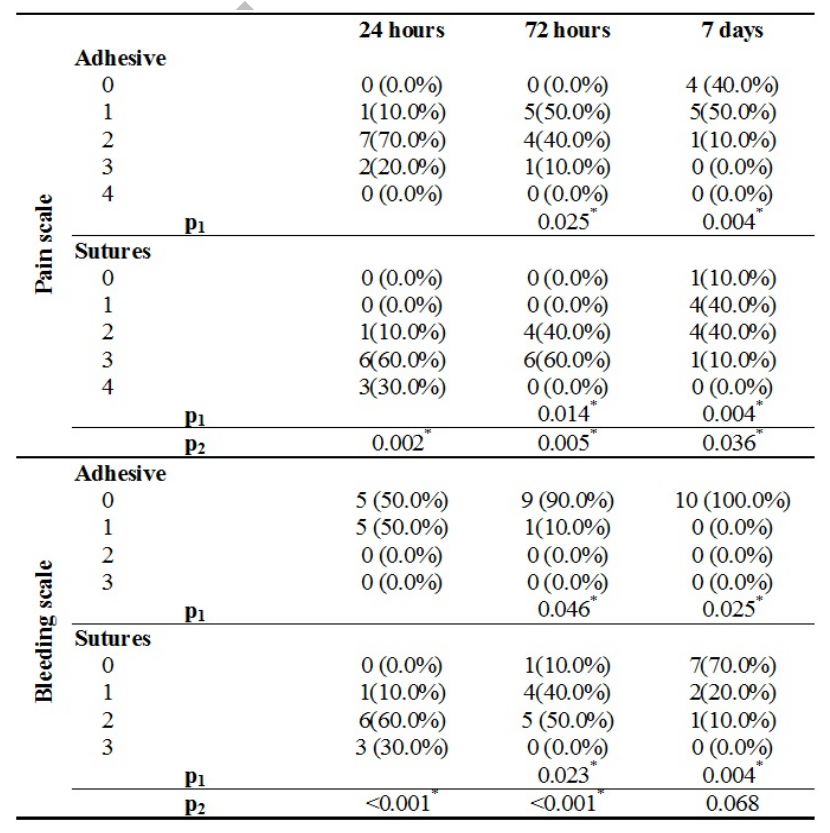

Qualitative data were described using number and percent

$\mathrm{p}_{1}$ : $\mathrm{p}$ value for Wilcoxon signed ranks test for comparing between preoperative with each other period in each group $p_{2}: p$ value for Mann Whitney test for comparing between the two studied groups *: Statistically significant at $\mathrm{p}=0.05$

\section{4- Facial swelling:}

On the first day of surgery, there was no significant difference between both groups concerning the postoperative edema as the patients of both groups showed elevated dimensions of (Tragus-commisure) (P 0.418).

Although the edema was less remarked on the third day and was much more reduced after one week post-operatively in both groups, the difference was also not that significant (P 0.360) and ( $P$ 0.275) in both periods. However the recovery was faster in the adhesive group. Data analysis is explained in Table (2).

\section{5- Local reaction / Infection}

Statistical analysis has revealed no significant difference between both groups on the first and third days postoperatively, however the result were significantly different after 7 days post-operatively as the sutures group showed the presence of tissue local infection in some cases. The bacteriostatic effect of cyanoacrylates may be the main reason for such result on the seventh postoperative day. Data analysis is explained in Table (3). 


\section{6- Wound dehiscence / gaping}

Data analysis showed no significant difference between both groups in wound dehiscence assessment after 2 days, 3 days and 7 days. Data analysis is explained in Table (3).

Table (2): Comparison between the two studied groups according to trismus and edema

\begin{tabular}{|c|c|c|c|c|c|c|}
\hline & & Preoperative & 24 hours & $\begin{array}{l}\text { After } \\
\mathbf{3} \text { days }\end{array}$ & 7 days & $\mathbf{p}_{1}$ \\
\hline \multirow{5}{*}{ 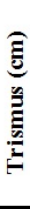 } & Adhesive & $4.62 \pm 0.52$ & $3.31 \pm 0.56$ & $3.64 \pm 0.50$ & $4.05 \pm 0.43$ & $<0.001^{*}$ \\
\hline & $\mathbf{p}_{2}$ & & $<0.001^{*}$ & $<0.001^{*}$ & $<0.001^{*}$ & \\
\hline & Sutures & $4.31 \pm 0.46$ & $2.56 \pm 0.45$ & $2.89 \pm 0.41$ & $3.42 \pm 0.39$ & $<0.001^{*}$ \\
\hline & $\mathbf{p}_{2}$ & & $<0.001^{*}$ & $<0.001^{*}$ & $<0.001^{*}$ & \\
\hline & $\mathbf{p}_{3}$ & 0.175 & $0.004^{*}$ & $0.002^{*}$ & $0.003^{*}$ & \\
\hline \multirow{5}{*}{ 졸 } & Adhesive & $39.38 \pm 3.39$ & $44.24 \pm 3.21$ & $43.10 \pm 3.31$ & $41.41-3.69$ & $<0.001^{*}$ \\
\hline & $\mathbf{p}_{2}$ & & $<0.001^{*}$ & $<0.001^{*}$ & $<0.001^{*}$ & \\
\hline & Sutures & $39.71 \pm 2.22$ & $45.26 \pm 2.21$ & $44.25 \pm 1.96$ & $42.91 \pm 2.05$ & $<0.001^{*}$ \\
\hline & $\mathbf{p}_{2}$ & & $<0.001^{*}$ & $<0.001^{*}$ & $<0.001^{*}$ & \\
\hline & $\mathbf{p}_{3}$ & 0.800 & 0.418 & 0.360 & 0.275 & \\
\hline
\end{tabular}

Normally distributed data was expressed in mean $\pm \mathrm{SD}$

$p_{1}: p$ value for $F$ test (ANOVA) with repeated measures for comparing between the different studied periods

$\mathrm{p}_{2}$ : Stands for adjusted Bonferroni p-value for ANOVA with repeated measures for comparison between Preoperative with each other period in each group

$p_{3}: p$ value for Student t-test for comparing between the two studied groups

*: Statistically significant at $\mathrm{p}=0.05$

Table (3): Comparison between the two studied groups according to local reaction and wound dehiscence

\begin{tabular}{|c|c|c|c|c|}
\hline & & 24 hours & 72 hours & 7 days \\
\hline \multirow{9}{*}{ 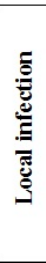 } & Adhesive & & & \\
\hline & Negative & $10(100.0 \%)$ & $10(100.0 \%)$ & $10(100.0 \%)$ \\
\hline & Positive & $0(0.0 \%)$ & $0(0.0 \%)$ & $0(0.0 \%)$ \\
\hline & $\mathbf{p}_{1}$ & - & - & - \\
\hline & Sutures & & & \\
\hline & Negative & $10(100.0 \%)$ & $8(80.0 \%)$ & $6(60.0 \%)$ \\
\hline & Positive & $0(0.0 \%)$ & $2(20.0 \%)$ & $4(40.0 \%)$ \\
\hline & $\mathbf{p}_{1}$ & & 0.500 & $0.025347^{*}$ \\
\hline & $p_{2}$ & - & 0.474 & 0.043344 \\
\hline \multirow{9}{*}{ 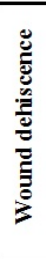 } & Adhesive & & & \\
\hline & Negative & $10(100.0 \%)$ & $9(90.0 \%)$ & $9(90.0 \%)$ \\
\hline & Positive & $0(0.0 \%)$ & $1(10.0 \%)$ & $1(10.0 \%)$ \\
\hline & $\mathbf{p}_{1}$ & & 1.000 & 1.000 \\
\hline & Sutures & & & \\
\hline & Negative & $10(100.0 \%)$ & $7(70.0 \%)$ & $6(60.0 \%)$ \\
\hline & Positive & $0(0.0 \%)$ & $3(30.0 \%)$ & $4(40.0 \%)$ \\
\hline & $\mathbf{p}_{1}$ & & 0.250 & 0.125 \\
\hline & $\mathrm{p}_{2}$ & - & 0.582 & 0.303 \\
\hline
\end{tabular}

Qualitative data were described using number and percent .

$p_{1}: p$ value for McNemar test for comparing between preoperative with each other period in each group . $p_{2}: p$ value for Fisher Exact test for comparing between the two studied groups

*: Statistically significant at $p=0.05$

\section{DISCUSSION}

In the present study, after the comparison between N-butyl cyanocrylate adhesive and sutures in the closure of the mucoperiosteal flaps after the surgical removal of the mandibular third molars, it was found that the adhesive had better results with pain, hemostasis, trismus and local reaction of tissues. Concerning the wound dehiscence and swelling parameters were nearly the same in both groups.

Ghoreishian $\mathrm{M}$ et al (4) performed a controlled clinical trial study of sixteen patients with similar bone impaction, cyanoacrylate and 3-0 silk suture were used for incision closure. After bone removal and tooth removal, one side incision was closed using cyanoacrylate and other side with 3-0 silk sutures. Study suggested that the use of cyanoacrylate resulted in better haemostasis, this result is in accordance to our study concerning bleeding.

In a clinical comparison made between N-butyl cyanoacrylate and sutures after the closure of surgical wounds in both study and control groups respectively. The clinical observations revealed excellent results obtained from the study groups compared to the control group. The immediate permanent hemostasis and the rapid formation of a strong bond across the wound edges were described by many authors after the application of N-butyl cyanoacrylate adhesive (23-25).

In a study testing Iso-amyl-cyanoacrylate adhesive compared to sutures after the removal of impacted mandibular third molar, the clinical evaluation on the first three days revealed that pain and edema were apparently higher in the sutured wounds in contrast with the adhesive side. Covering the wound with cyanoacrylate has great advantages of reduced post-operative pain. This may be explained by the fact that the formaldehyde - one of the degeneration products of cyanoacrylates- causes mild local anesthesia in the covered area (26).

The N-butyl cyanoacrylate adhesive as named, the normal cyanoacrylate which is biologically accepted by the tissues, was compared to Iso-amyl-cyanoacrylate adhesive , they showed the same biological tolerance based on histomorphologic bases after tissue -tolerance experiments (26) .

In a study conducted to compare 3-0 silk suture and tissue adhesive N-butyl-2-cyanoacrylate in closure of intra-oral surgical incisions.Twenty patients were randomly divided into two equal groups. N-butyl-2-cyanoacrylate showed a better intimate healing with no gaps compared to use of silk suture. The author concluded that the use of N-butyl-2cyanoacrylate reduces patient discomfort and irritation and it is an easy and effective way in managing intraoral wounds. This result also is in accordance to our results concerning pain (26).

Knott et al (27) performed a study using Octyl-2Cyanoacrylate in the repair of congenital cleft lip. The results compared to conventional sutures appreciated the advantage of watertight closure of the tissue adhesive which is bacteriostatic, as it minimizes exposure to nasal secretion which has high bacterial count. This result is in accordance with our results concerning wound dehiscence and local tissue reaction.

Since the N-butyl cyanoacrylate is biologically tolerable as the Iso-amyl-cyanoacrylate - as previously mentioned, It was reported that Iso-amyl cyanoacrylate had a bacteriostatic effect against gram positive micro-organisms, and it had bactericidal activity against 10 test bacilli when 
the adhesive was used to stop CSF leaks during orbital surgery (28).

The irritation and trauma from the sutures and collection of food particles at the sutured site are probably responsible for the reaction, moreover the blood coagulum that filled the defect to protect the wound was affected by the fibrinolytic effect of the salivary secretion. In cyanoacrylate sites the wound was isolated with the adhesive to allow healing without interference, where the healing pattern was quick, uniform, with less inflammatory response. Also sutureless wound closure was reported to be a preferable method than conventional suture techniques (29).

It was marked that the N-butyl cyanoacrylate has been a time saving material for wound repair, providing a flexible water-tight protective coating that eliminate the need for suture removal especially in superficial wounds as it showed confident wound closure of acceptable results (30).

A study conducted on 15 patients, who underwent root resections of the upper incisors on both sides, the incision lines were closed with silk sutures on one side and by $\mathrm{N}$ butyl-2-cyanoacrylate on the other side of the frenum. Postoperative clinical evaluation in the first three days revealed that pain was significantly higher in sutured side. The author concluded that N-butyl cyanoacrylate, as a tissue adhesive, is not cytotoxic in vivo and can be used as an alternative to sutures in oral surgical procedures. This result is in accordance with our research results concerning pain (5).

A study that compared three cyanoacrylate-based adhesives, the results were similar among the groups after the long-term experimental period. However, after the short period, n-butyl-cyanoacrylate and ester cyanoacrylate were more biocompatible with less inflammation elicited. These results are in accordance with our results concerning pain and trismus (31).

A study conducted in 2007 to compare the bacteriostatic effects, corneal cytotoxicity, and ability to seal corneal incisions among fibrin glue and 2 commercially available cyanoacrylate derivatives: N-butyl cyanoacrylate and methoxy-propyl-cyanoacrylate. The study showed that Methoxypropyl cyanoacrylate and N-butyl cyanoacrylate displayed a greater ability to seal corneal incisions and showed great levels of bacteriostasis. This result is in accordance to our results (32).

\section{CONCLUSIONS}

Cyanoacylates are highly effective bacteriostatic and hemostatic agents; they are well-tolerated by tissues. They can be applied with ease, they require little professional skill in their application, therefore their use in surgical purposes proved to be as efficient as surgical sutures.

Treatment with cyanoacrylates may require some precautions as they stick nearly to all materials and tissues.

\section{CONFLICT OF INTEREST}

The authors declare that they have no conflicts of interest.

\section{REFERENCES}

1. Kruger GO. Textbook of Oral and Maxillofacial surgery, 6th (ed) ;St. Louis: Mosby. 1984. 1-3.

2. Kwon PH, Laskin DM. Clinicians' manual of Oral and Maxillofacial surgery.3rd (ed). Quintessence Publishing Co. Incorporation. Chicago 2001. 241-50.

3. Killey HC, Kay LW, Seward GR, Harris M, McGowan AD. Killey and Kay's Outline of Oral Surgery. Part 1, 2nd (ed). Wright Bristol; 1987:28-42.

4. Ghoreishian M, Gheisari R, Fayazi M. Tissue adhesive and suturing for closure of the surgical wound after removal of impacted mandibular third molars: a comparative study. Oral Surg Oral Med Oral Pathol Oral Radiol Endod 2009;108:e14-6.

5. Giray CB, Atasever A, Durgun B, Araz K. Clinical electron microscope comparison of silk sutures and Nbutyl-2-cyanoacrylate in human mucosa. Aust Dent J 1997;42: 225-8.

6. Buckley MJ, Beckman EJ. Adhesive use in oral and maxillofacial surgery. Oral Maxillofac Surg Clin North Am 2010;22:195-9.

7. Gogulanathan M, Elavenil P, Gnanam A, Raja VB. Evaluation of fibrin sealant as a wound closure agent in mandibular third molar surgery-a prospective, randomized controlled clinical trial. Int $J$ Oral Maxillofac Surg 2015; 44: 871-5.

8. Bimal J, Trivedi A, Bhavsar N. Use of fibrin glue in periodontal flap surgery. J Indian Soc Periodontol 2008;12:21-5.

9. Adler N, Nachumovsky S, Meshulam-Derazon S, Ad-El D. Skin graft fixation with cyanoacrylate tissue adhesive in burn patients. BURNS 2007;33:803.

10. Kulkarni S. Healing of periodontal flaps when closed with silk sutures and N-butyl cyanoacrylate: a clinical and histological study. Ind J Den Res 2007;18:72-7.

11. Singer AJ, Quinn JV, Hollander JE. The cyanoacrylate topical skin adhesives. Am J Emerg Med 2008;26:490-6.

12. Daniel P, Zins JE, Banbury J, Djohan R, Yetman RJ, Papay F. A comparison of dermabond tissue adhesive and sutures in the primary repair of the congenital cleft lip. Ann Plast Surg 2007;58:121-5.

13. Toriumi M, Raslan F, Friedman M, Eugene M, Tardy J. Variable histotoxicity of histoacryl when used in a subcutaneous site: an experimental study.Laryngoscope. 1991; 101: 339-43.

14. Kaplan M, Bozkurt S, Kut MS, Kullu S, Demirtas MM. Histopathological effects of ethyl 2-cyanoacrylate tissue adhesive following surgical application: an experimental study. Eur J Cardiothorac Surg 2004;25:167-72.

15. Mourougayan V. Sutureless skin closure for cleft lip repair. Cleft Palate Craniofac J 2006;43:656-8.

16. Perin LF, Helene A, Fraga MF. Sutureless closure of the upper eyelids in blepharoplasty: use of octyl-2cyanoacrylate. Aesthet Surg J 2009;29:87-92.

17. Elgazzar RF, Abdulmajeed I, Mutabbakani M. Cyanoacrylate glue versus suture in peripheral nerve 
reanastomosis. Oral Surg Oral Med Oral Pathol Oral Radiol Endod 2007;104:465-72.

18. Arunachalam P, King PA, Orford J. A prospective comparison of tissue glue versus sutures for circumcision. Int J Pediatr Surg 2003;19:18-9.

19. Cohen K, Diegelman RF, Lindblat WJ. Wound Healing: Biochemical and Clinical Aspects. WBSaunders Co. 1992.

20. Khalil HS, Elshall MA, Harbi YA, Asmar SA, Wadee MA. Healing of oral surgical wounds using 3/0 silk suture and n-butyl cyanoacrylate tissue adhesive. Egypt Dent J 2009;55:2607.

21. Pell G, Gregory B. Impacted mandibular third molars: classification and modified techniques for removal. Dent Diag 1993;39:330-8.

22. Gabka J, Matsumara T. Measuring techniques and clinical testing of an anti- inflammatory agent (tantum). Munch Med Wochenschr 1971;113:198-203.

23. Al-Belasy FA, Amer MZ. Hemostatic effect of n-butyl2-cyanoacrylate (histoacryl) glue in warfarin-treated patients undergoing oral surgery. J Oral Maxillofac Surg 2003;61:1405-9.

24. Pérez M, Fernández I, Márquez D, Bretaña RM. Use of N-butyl-2-cyanoacrylate in oral surgery: biological and clinical evaluation. Artificial Organs2000;24:241-3.

25. Joshi AD, Saluja H, Mahindra U, Halli R. A comparative study: efficacy of tissue glue and sutures after impacted mandibular third molar removal. J Oral Maxillofac Surg 2011;10:310-5.

26. Vastani A, Maria A. Healing of Intraoral Wounds Closed Using Silk Sutures and Isoamyl 2-Cyanoacrylate Glue: A Comparative Clinical and Histologic Study. J Oral Maxillofac Surg 2013; 71:241-8.

27. Knott PD, Zins JE, Banbury J, Djohan R, Yetman RJ, Papay F. A comparison of dermabond tissue adhesive and sutures in the primary repair of the congenital cleft lip. Ann Plast Surg 2007;58:121-5.

28. Tse DT, Panje WR, Anderson RL. Cyanoacrylate adhesive used to stop CSF leaks during orbital surgery. Arch Ophthalmol 1984;102:1337-9.

29. Avery JK. Oral Development and Histology, $2^{\text {nd }}$ (ed).Williams and Wilkins. 1994;22:192-210.

30. Bruns TB, Worthinton JM. Using Tissue adhesive for wound repair: A practical guide to Dermobond. Am Fam Physician 2000;61:1383-8.

31. deAzevedo CL, Marques MM, Bombana AC. Cytotoxic effects of cyanoacrylates used as retrograde filling materials: an in vitro analysis. Pesqui Odontol Bras 2003; 17:113-8.

32. Chen WL, Lin CT, Hsieh CY, Tu IH, Chen WY, Hu FR. Comparison of the bacteriostatic effects, corneal cytotoxicity, and the ability to seal corneal incisions among three different tissue adhesives. Cornea 2007;26:1228-34. 